\title{
Anticoagulation in primary care - a cross sectional study in 14 heterogeneous countries
}

\author{
Sven Streit ${ }^{a}$, Richard Roberts ${ }^{b}$, Robert Anders Burman ${ }^{c}$, Persijn J. Honkoop ${ }^{d}$, Damian N. Meli ${ }^{a}$ \\ a Institute of General Practice, University of Bern, Switzerland \\ b University of Wisconsin, Madison, Wisconsin, USA \\ c National Centre for Emergency Primary Health Care, Uni Health, Norway \\ d Department of Public Health and Primary Care, Leiden University Medical Centre, The Netherlands
}

\section{Summary}

Background: New oral anticoagulants (NOACs) are predicted to become the new standard treatment for stroke prevention in patients with atrial fibrillation, and may replace vitamin $\mathrm{K}$ antagonists (VKAs). NOACs are prescribed less than expected, even though they do not require international normalised ratio (INR) monitoring. In this study we assessed methods for INR monitoring after the introduction of NOACs a in heterogeneous sample of countries.

Methods: We asked representatives of the Vasco da Gama Movement, a network of junior and future general practitioners (GPs) in Europe, and WONCA, the World Organization of Family Doctors, to describe the way INR is monitored in their respective countries.

Results: Representatives of 14 countries responded. In most countries, the INR is monitored by GPs; in some countries, these patients are treated by other specialists or in specialised anticoagulation centres. In only a few countries, anticoagulated patients monitor the INR themselves.

Conclusion: Our study showed several strategies for managing anticoagulation in different countries. In most countries, the INR is monitored by GPs. These consultations offer opportunities to address other issues, such as blood pressure control or medication adherence. These factors may be considered when deciding to switch patients from VKAs to NOACs.

Key words: anticoagulation; INR monitoring; worldwide

\section{Introduction}

New oral anticoagulants (NOACs) have become available in recent years, with the main advantage of a fixed oral dosage, so that the regular assessment of interna-

Funding / potential competing interests: No financial support and no other potential conflict of interest relevant to this article was reported. tional normalised ratio (INR) values and subsequent dosage adjustment of vitamin $K$ antagonists (VKAs) by a professional was no longer required. Owing to their efficacy and noninferiority to VKAs,
NOACs "appear to hit the sweet spot of both improved efficacy and safety" [1] and they were expected to become the new standard treatment for stroke prevention in patients with atrial fibrillation $(\mathrm{AF})$.

However, even though NOACs have been available for some time, opinion remains divided about implementing them. In recent studies several reasons that may explain a lack of implementation were mentioned. First, patients or general practitioners (GPs) may not want to switch, because they are familiar and comfortable with VKAs when INR values are consistently in therapeutic range [1], or because they are comfortable with managing perioperative adjustments in VKA dosing [2]. Second, studies have not shown an increase in the quality of life for patients using NOACs compared to VKA (measured as quality-adjusted life years) [3]. Third, in patients with good or excellent control, switching to NOACs may cause additional risk of major gastrointestinal bleeding or other adverse effects [4]. There are well-validated strategies for the management of bleeding complications, should they occur, when using a VKA [5], but these are currently not available for NOACs.

Another issue complicating matters is that current practice of VKA treatment is different all over the world. To gain insight into current anticoagulation practice and the rationale behind choice of therapy, we undertook this survey to provide an overview of anticoagulant therapy from diverse countries after the introduction of NOACs.

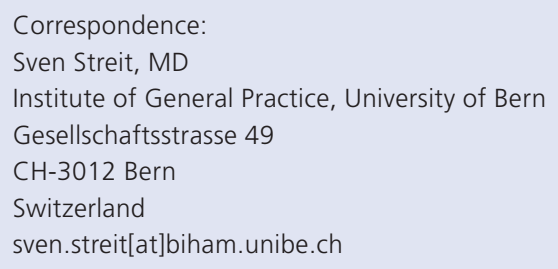




\section{Methods}

We assessed the way INR is monitored in a crosssectional study by using a questionnaire. The questionnaire was sent to all members of the Vasco da Gama Movement (VdGM), a network of junior and future GPs, which includes at least one member from most countries in Europe. We also sent the questionnaire to family doctors identified through the World Organization of Family Doctors (WONCA), in order to reach more remote countries. Since the participants in the survey were GPs or trainees involved in international collaboration, the validity of their knowledge of their countries' systems was relatively high.

The questionnaire was sent at the beginning of October 2012 and consisted of a case of an 80-year-old man with $\mathrm{AF}$ who needs anticoagulation treatment because of his CHADS2 score, without any contraindications. Respondents were asked to describe how this patient would be treated in their country and who would do the follow-up.

Figure 1

Overview of replying countries: Chile, China, Finland, Greece, Israel, Italy, Nepal, Netherlands, Norway, Panama, Slovenia, Switzerland, Turkey, United States of America.

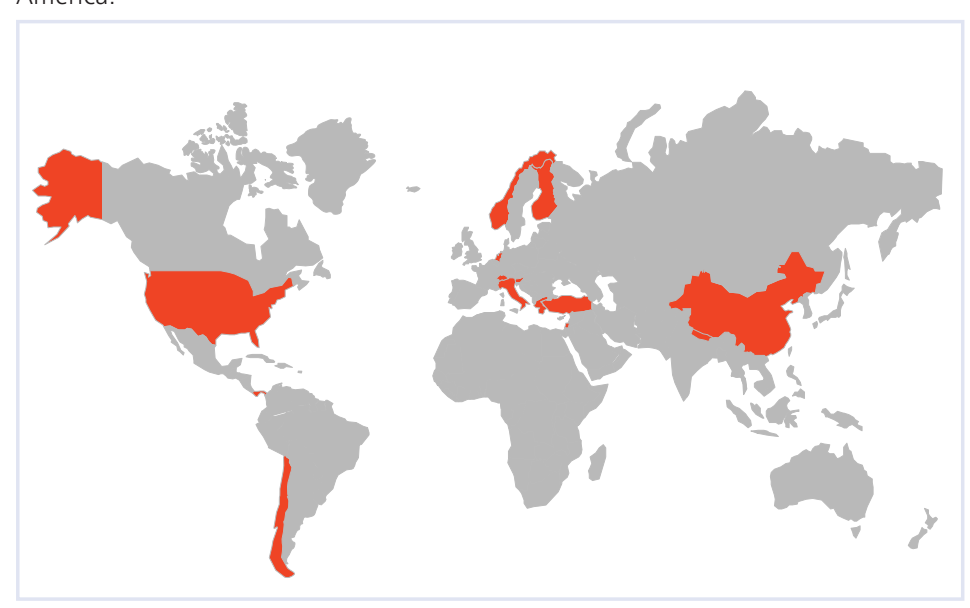

Figure 2

Different methods for monitoring INR in different countries. The $x$-axis represents the number of mentions of each method per questionnaire. Multiple answers were possible.

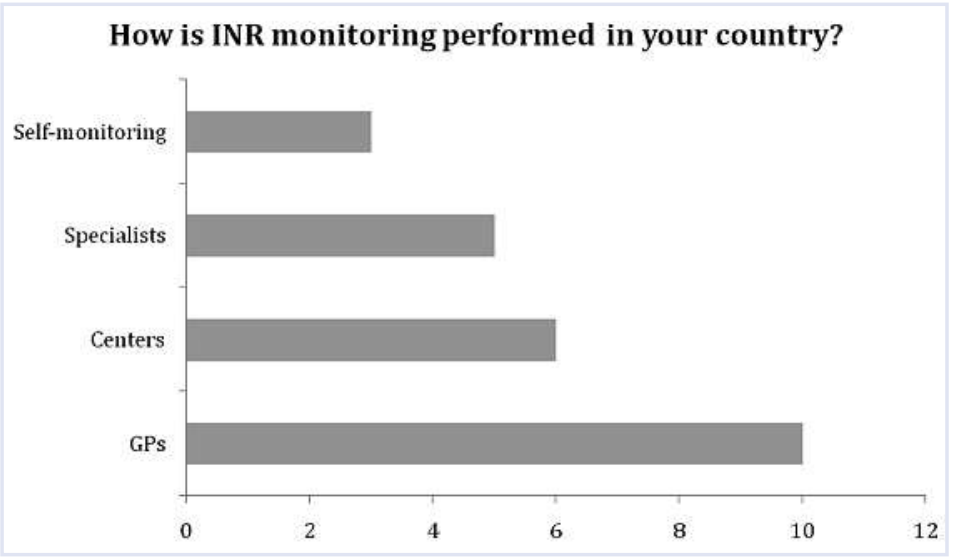

\section{Results}

The questionnaire was sent to 40 different countries of which 14 responded (response rate 35\%) (fig. 1). In table 1 we provide an overview of the description of anticoagulation therapy in these countries. If monitoring was performed in different settings in a country (e.g., by GPs and anticoagulation centres), it was counted once for each measure. INR monitoring is performed by GPs in ten $(71 \%)$ countries, by other specialists in six (43\%), by specialised anticoagulation centres in five (36\%) countries, and by the patients themselves in three (21\%) countries (fig. 2). Totals add up to more than $100 \%$ because some countries had more than one mode of monitoring.

Respondents stated that an advantage of prescribing VKAs was that consultations for managing anti-coagulation also offered opportunities to address other conditions for patients with multimorbidity, which is especially prominent in these patients. While some respondents mentioned higher costs as limiting the use of NOACs, others believed that seeing patients on a regular base is necessary to prevent loss of quality of care (appendix A).

\section{Discussion}

\section{Summary of the main findings}

This study provided an overview of current anticoagulation therapy management in general practice from 14 different countries. In most countries, the INR is still monitored by GPs, in some countries it is monitored by specialists or at specialised centres and in only a few countries do patients self-manage their VKA dosage. Some respondents were critical of the use of NOACs, since many patients requiring anticoagulation therapy suffer from several other diseases, which can also be addressed during anticoagulation consultations.

\section{Strengths and limitations}

The main strength of our study is that we provide an overview from a heterogeneous sample of countries from all over the world. One limitation of our study is that the sample is small and the response rate of $35 \%$ was low. However, it does demonstrate the variety of strategies for managing and monitoring anti-coagulation all over the world. Another limitation is that one person described the situation for a country. Since the respondents are active members of their national organisations and participate actively in international activities, they have relatively high knowledge of their health care systems and this should not have influenced results.

\section{Interpretation in relation to current literature}

The uncertainty surrounding the choice of anticoagulants is reflected in recommendations in international guidelines [6]. The American College of Cardiology 
Table 1

Different methods of measuring and monitoring international normalised ratio (INR) in 14 countries around the world.

\begin{tabular}{|c|c|}
\hline Country & INR monitoring \\
\hline Chile & $\begin{array}{l}\text { Both in private clinics and in public hospitals there are policlinics for anticoagulation where a patient's } \\
\text { INR is monitored. These clinics are run by internists who see patients and evaluate the dosage. In rural areas, } \\
\text { this is carried out by GPs. }\end{array}$ \\
\hline $\begin{array}{l}\text { China } \\
\text { (Hong Kong } \\
\text { and Mainland) }\end{array}$ & $\begin{array}{l}\text { In both Mainland China and Hong Kong, most warfarin is prescribed and monitored by internists at hospital clinics. } \\
\text { For most cases, the attending physician arranges for the INR to be checked in the laboratory before } \\
\text { every follow up visit. In Hong Kong, INR monitoring is also provided by family physicians at family medicine specialist } \\
\text { clinics or at community health clinics. In Mainland China, general practitioners in community health centres also help } \\
\text { in monitoring warfarin treatment. The use of new oral anticoagulants is limited, which is mainly related to their high } \\
\text { cost. }\end{array}$ \\
\hline Finland & $\begin{array}{l}\text { Most of the patients get their INR monitored in health centres by their GP or a nurse. Most commonly, } \\
\text { the patient visits a laboratory and after that calls the healthcare centre and is informed of the new dosage. Recently } \\
\text { there are new ways. Some of the patients are trained to perform self-monitoring and they receive } \\
\text { their INR values directly from laboratory as a text message to their mobile phones. Sometimes nurses evaluate the } \\
\text { dosage and send that to the patient via eLetter by normal mail or via the Web where patients have a link } \\
\text { to their e-mail and get the dosage in a special Web portal at same time that it is sent. Of course if the INR value is } \\
\text { very high or low the nurse will call them and make sure that they receive the new dosage. Elderly people can have } \\
\text { their INR monitored at home by their home-care nurses. }\end{array}$ \\
\hline Greece & $\begin{array}{l}\text { GPs do not start the initial therapy with anticoagulants in AF but they can monitor the INR if they want } \\
\text { and know how to. The patient goes to the hospital or to a private microbiologist and has a blood check every } \\
4 \text { to } 6 \text { weeks if stable. Then he presents the results to either the cardiologist, internal medicine doctor or GP, } \\
\text { depending on who is most accessible. }\end{array}$ \\
\hline Israel & $\begin{array}{l}\text { INR monitoring is done by GPs. The patients have regular blood checks in their clinic (usually the neighbourhood } \\
\text { clinic), taken by a nurse. The result is emailed to their personal GP, and they can see it on the Web too. Usually the GP } \\
\text { calls them and lets them know about the change needed in the warfarin dose. There are some clinics with on-the- } \\
\text { spot INR machines, and again the GP gets the result and tells the patient what to do. }\end{array}$ \\
\hline Italy & $\begin{array}{l}\text { In urban centres, a GP who first evaluates such a patient refers him to the nearest centre for oral anticoagulant } \\
\text { therapy: these centres consists of a laboratory, a cardiologist and a nurse. These centres measure the INR and initiate } \\
\text { therapy. They follow up the patients and adjust the dosage accordingly (this is usually done by the cardiologist). Each } \\
\text { patient informs the centre of changes in their medication so that they adjust the frequency } \\
\text { of the INR measurements and the dosage adjustment. In rural areas where these centres don't exist, GPs manage the } \\
\text { dosing by themselves. The INR measurement is usually carried out in laboratories in the nearby health centres. }\end{array}$ \\
\hline Nepal & Patients are sent to a laboratory. With the report they go to their GP or internist for dosage monitoring. \\
\hline Netherlands & $\begin{array}{l}\text { There is a special organisation that measures the INR and provides patients with the dosage for their vitamin K } \\
\text { antagonist. They work entirely independent of GPs and hospitals. Even when the INR is much too high they themsel- } \\
\text { ves will give vitamin K. }\end{array}$ \\
\hline Norway & $\begin{array}{l}\text { Most patients get their INR measured at their general practice every } 4 \text { to } 6 \text { weeks if stable, and more often if } \\
\text { unstable. The GPs manage this quite differently. Almost every patient gets blood drawn by a health secretary / nurse } \\
\text { at the clinic, or a nurse brings a blood sample to the clinic if the patient is house-bound / not mobile. } \\
\text { Then some GPs have "normal" length consultations ( } 15 / 20 \text { minutes) for every INR control, other have short consulta- } \\
\text { tions in their calendar ( } 5 / 10 \text { minutes), and others again just tell their patients to drop by, and they } \\
\text { call them in after the INR is ready, between other patients. Some young and quite healthy patients do their } \\
\text { own testing and dosage adjustments. }\end{array}$ \\
\hline Panama & $\begin{array}{l}\text { It is more complex in the public health system. INR is measured only in a blood sample taken from the arm, } \\
\text { not capillary, and the result is usually not the same day. GPs may see the patient and change the dose, though often } \\
\text { patients are sent to an anticoagulation clinic with internists, where the laboratory test result is the same day. } \\
\text { However, this clinic is only in Panama City in the tertiaryl hospital. In the private sector INR results are available the } \\
\text { same day, and mostly adjusted by internists. }\end{array}$ \\
\hline Slovenia & $\begin{array}{l}\text { Usually internal medicine specialists monitor INR at hospitals and at some bigger primary health centres. Specially } \\
\text { trained GPs run this service in smaller primary health centres and in primary-care private settings. } \\
\text { There is a trend, that INR monitoring should be more widely performed at the primary-care level. } \\
\text { Self-monitoring is unusual in Slovenia. Also NOACs are rarely used, due to high prices and prescription } \\
\text { restrictions which are set by Slovenia's national health insurance company. }\end{array}$ \\
\hline Switzerland & $\begin{array}{l}\text { Most patients are monitored by their GP with a point-of-care device so the INR result is instantly available. } \\
\text { Some patients are trained to perform self-monitoring. }\end{array}$ \\
\hline Turkey & The patients regularly go to an internal medicine specialist who monitors and changes the dosage. \\
\hline United States & $\begin{array}{l}\text { Mostly family doctors have the blood drawn at their practice, but send the specimen to a reference or hospital } \\
\text { laboratory, and then call the patient later with the results and advice on management of the anticoagulation. Some } \\
\text { health systems have a pharmacist call the patient instead. }\end{array}$ \\
\hline
\end{tabular}


Foundation / American Heart Association Task Force on Practice Guidelines note "Because of ... the greater risk of non-hemorrhagic side effects ... patients already taking warfarin with excellent INR control may have little to gain by switching ....". On the other hand, a systematic review including $>50,000$ patients on NOACs showed a significant reduction in major and intracranial bleeding compared with VKAs [7].

Studies suggest that the accessibility of primarycare practice may affect the efficiency and effectiveness of oral anticoagulation management. Proposed strategies to improve monitoring access in primary care include careful follow-up of patient adherence and missed appointments [8], same-day availability of laboratory results, comprehensive patient education [9], training of other healthcare personnel to oversee monitoring, and various self-care models [10]. Thus, the use of VKAs may still improve, which would further diminish the advantages of anticoagulation drugs such as NOACs that do not require monitoring.

\section{Implications for clinical practice}

The management of multimorbidity is a key issue for GPs. The use of VKAs gives patients the opportunity to have regular contact with their GP's practice, and regular measurement of INR levels provides insights on patient comprehension and compliance. After switching to NOACs, valuable knowledge about adherence may be lost. Therefore, we speculate that switching to NOACs not only affects stroke prevention, bleeding rates, the inconvenience of INR monitoring and costs, but also has an impact on the quality of care of patients with multimorbidity.

\section{Conclusion}

Using a global network of GPs, we provided insight into current anticoagulation therapy in 14 countries in different parts of the world. In summary, although several strategies for monitoring INR are being used in daily practice, in most countries primary-care physicians provide INR monitoring. Respondent GPs also raised critical issues about the loss of opportunities to provide additional care to their patients when they visit for INR monitoring, which is especially important since multimorbidity is often prevalent in patients on anticoagulants. This additional factor may be considered when deciding whether to switch from VKA to NOAC anti-coagulation.

Acknowledgements: We thank the following contributors for giving us insight in their nation's way of monitoring INR by answering this study's questionnaire (in alphabetic order): Zelal Akbayin (Turkey), Javier Besomi (Chile), Ronen Brand (Israel), Eleni Chovarda (Greece), Marko Drešček (Slovenia), Charilaos Lygidakis (Italy), Essie Maduro (Panama), Marjo Parkkila-Harju (Finnland), Pramendra Prasad Gupta (Nepal), Frances Yu (Hong Kong).

\section{References}

1 Ru San T, Chan MY, Wee Siong T, Kok Foo T, Kheng Siang N, Lee SH, et al. Stroke prevention in atrial fibrillation: understanding the new oral anticoagulants dabigatran, rivaroxaban, and apixaban. Thrombosis. 2012;2012:108983. doi: 10.1155/2012/108983. PubMed PMID: 22997573; PubMed Central PMCID: PMC3444866.

2 Jamula E, Schwalm JD, Douketis JD. Periprocedural anticoagulation practices in warfarin-treated patients who require elective angiography with or without percutaneous coronary intervention: a retrospective chart review. Thromb Res. 2010;125(4):351-2. doi: 10.1016/j.thromres.2009.10.015. PubMed PMID: 19919877.

3 Barcellona D, Contu P, Sorano GG, Pengo V, Marongiu F. The management of oral anticoagulant therapy: the patient's point of view. Thromb Haemost. 2000;83(1):49-53. PubMed PMID: 10669154.

4 Connolly SJ, Ezekowitz MD, Yusuf S, Eikelboom J, Oldgren J, Parekh A, et al. Dabigatran versus warfarin in patients with atrial fibrillation. $\mathrm{N}$ Engl J Med. 2009;361(12):1139-51. doi: 10.1056/NEJMoa0905561. PubMed PMID: 19717844

5 Schulman S, Crowther MA. How I treat with anticoagulants in 2012: new and old anticoagulants, and when and how to switch. Blood. 2012;119(13):3016-23. doi: 10.1182/blood-2011-10-378950. PubMed PMID: 22302737.

6 Wann LS, Curtis AB, Ellenbogen KA, Estes NA, 3rd, Ezekowitz MD, Jackman WM, et al. 2011 ACCF/AHA/HRS focused update on the management of patients with atrial fibrillation (update on dabigatran): a report of the American College of Cardiology Foundation/American Heart Association Task Force on practice guidelines. J Am Coll of Cardiol. 2011;57(11):1330-7. doi: 10.1016/j.jacc.2011.01.010. PubMed PMID: 21324629.

7 Dentali F, Riva N, Crowther M, Turpie AG, Lip GY, Ageno W. Efficacy and safety of the novel oral anticoagulants in atrial fibrillation: a systematic review and meta-analysis of the literature. Circulation. 2012;126(20):238191. doi: 10.1161/CIRCULATIONAHA.112.115410. PubMed PMID: 23071159.

8 Nast SL, Tierney MJ, McIlwain R. Anticoagulation management in remote primary care. Can Fam Physician. 2005;51:384-5. PubMed PMID: 16926932; PubMed Central PMCID: PMC1472961.

9 Jackson SL, Peterson GM, Bereznicki LR, Misan GM, Jupe DM, Vial JH. Improving the outcomes of anticoagulation in rural Australia: an evaluation of pharmacist-assisted monitoring of warfarin therapy. $\mathrm{J}$ Clin Pharm Ther. 2005;30(4):345-53. doi: 10.1111/j.1365-2710.2005. 00656.x. PubMed PMID: 15985048.

10 Hodge K, Janus E, Sundararajan V, Taylor S, Brand W, Ibrahim JE, et al. Coordinated anticoagulation management in a rural setting. Aust Fam Physician. 2008;37(4):280-3. PubMed PMID: 18398530.

\section{Appendix A}

Remark by a responding general practitioner on monitoring INR:

"About 10 years ago, we went to a point of care approach - the patient has an INR done by fingerstick at our practice and then sits down with our head nurse right after to discuss whether to continue or modify their current dose. The key difference is that it is our practice nurse (not someone calling from the hospital) who knows the patient, understands the importance of keeping the family doctor informed, and sits down to discuss INR results with the patient. One example I give is that my nurse told the patient to return the next day because she was concerned about possible depression, and I diagnosed him the next day as suicidal due to major depressive disorder. She likely saved his life by knowing him, and by getting him connected to me." 